\title{
Plastic Deformation of Iron Whiskers at Elevated Temperatures*
}

\author{
By Kyojiro KANEKO ${ }^{* *}$ and Akimitsu OKURA ${ }^{* * *}$
}

\begin{abstract}
Synopsis
Iron whiskers were examined by the tensile test in the temperature range from $20^{\circ}$ to $230^{\circ} \mathrm{C}$, and the stress-strain curves were obtained. In those curves serrations appeared in a certain range of thickness of whiskers and temperature. Microscopic observations of deformed whiskers showed that the serrations corresponded to heavy slip steps. The upper and lower yield stresses were also obtained as a function of the thickness and the temperature. The upper yield stress varied linearly with the logarithm of the reciprocal of the absolute temperature, and the lower yield stress gave a strong temperature dependence in the range of $20^{\circ}$ to $75^{\circ} \mathrm{C}$ and a weak one in $120^{\circ}$ to $230^{\circ} \mathrm{C}$. From those results it was concluded that the serration might be due to the formation of simple slip bands.
\end{abstract}

\section{Introduction}

Study on the mechanical properties of iron whiskers was begun by the well-known experiment of Brenner ${ }^{1)}$ in 1956, and pursued by other authors. ${ }^{2), 3)}$ Yoshida et al. ${ }^{4)}$ performed a dynamical experiment in which the stress-strain curves were obtained by using an Instron-type tensile machine. The present authors have studied the plastic behaviors of iron whiskers by using an Instron-type hard machine in the temperature range from $20^{\circ}$ to $230^{\circ} \mathrm{C}$.

The theory of yielding of materials is usually discussed according to the experimental fact of Johnston and Gilman ${ }^{5}$ and Petch equation. ${ }^{6)}$ Studies of the plastic deformation of bcc transition metals have been done less extensively than the studies of fcc metals because of the difficulties in preparing highly perfect and pure specimens. It is well known that the whisker is fairly perfect and pure material, and then it is interesting to carry out the qualitative observations and quantitative measurements of mechanical behaviors of iron whiskers.

In the present paper, it will be shown that the stress-strain curves of iron whiskers have serration phenomena which depend on the thickness and test temperature, and that the upper and lower yield points have the temperature dependence.

\section{Experimental Procedure}

Iron whiskers were provided by the hydrogen reduction $^{7)}$ of commercially pure $\mathrm{FeCl}_{2} \cdot n \mathrm{H}_{2} \mathrm{O}$ at $670^{\circ}$ to $750^{\circ} \mathrm{C}$ for $3 \mathrm{hr}$ duration. ${ }^{8)}$ By the spectro-chemical analysis, amounts of inclusions were as follows; copper; 13.0 ppm, chromium; 2.0, tin; 0.5, titanium; 0.1 . After the reduction, the furnace was cooled slowly, and the specimens were cut and mounted on an Instron-

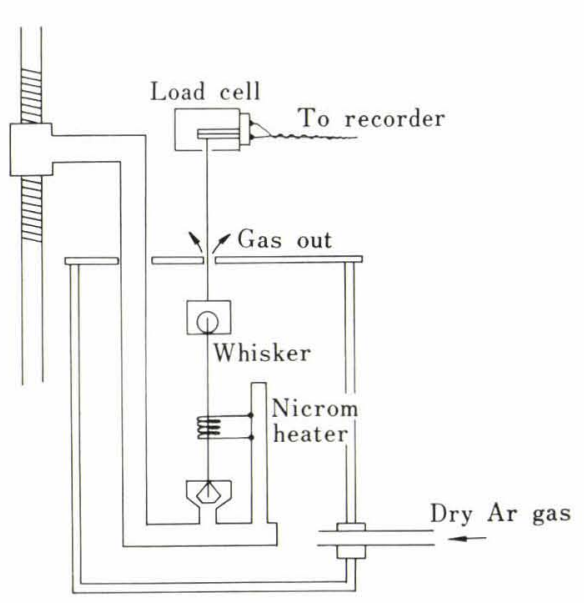

Fig. 1. Schematic illustration of the tensile machine for elevated temperature

type tensile machine by an adhesive agent as in Fig. 1. The adhesive agent was made by dissolving celluloid in acetone, and solidified within $10 \mathrm{~min}$ before tensile tests. Whiskers which have the $\langle 100\rangle$ growth direction and four $\{100\}$ lateral surfaces were selected as the specimens. The thickness (square-root of cross sectional area) of each specimen was measured by microscope with 750 magnification, and ranged from about 5 to $30 \mu$. The length of specimens ranged from 2 to $30 \mathrm{~mm}$ and the tensile strain rate was 0.1 to 1.0 per min. Due to the weakness of adhesive bond at higher temperatures, only a part of the specimen was heated by a nicrome wire in the temperature range $75^{\circ}$ to $230^{\circ} \mathrm{C}$ in argon atmosphere. The pen of the recorder could follow the stress-change when the stress increased, but not sufficiently follow abrupt stress drops.

\section{Experimental Results}

\section{Stress-Strain Curve}

\section{Room Temperature}

Figure 2 shows stress-strain curves of three specimens of different thickness. The stress and the strain are calculated as the tensile stress and the tensile strain. For the specimen of $4.9 \mu$ thickness the serration appeared as shown in Fig. 2 (a). For the specimen of $9.4 \mu$ thickness, the earlier half of the plastic deformation was distinguished from the latter half by presenting

* Originally published in Tetsu-to-Hagané, 57 (1971), 1714, in Japanese. English version received January 19, 1971.

** Formerly The Institute of Industrial Science, the University of Tokyo, Roppongi, Minato-ku, Tokyo 106, now at Department of Metallurgy, Faculty of Engineering, the University of Tokyo, Bunkyo-ku, Tokyo 113.

*** The Institute of Industrial Science, the University of Tokyo, Roppongi, Minato-ku, Tokyo 106. 


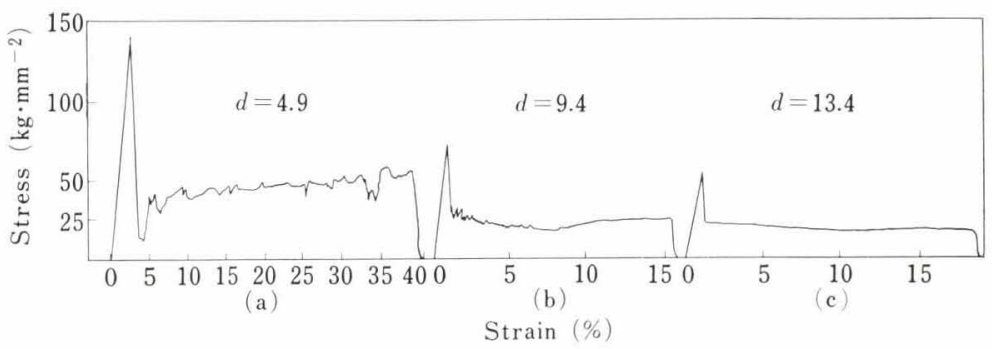

Fig. 2.

Stress-strain curves at room temperature at various thicknesses of whiskers. The tensile direction was $\langle 100\rangle$, and the strain rate was 0.1 to $1.0 / \mathrm{min}$. It was confirmed by the microscope during tests that the deformation was the Lüders nature. $d$ is the thickness in micron.

the serration and gradual decrease of flow stress as shown in Fig. 2 (b). Figure 2 (c) is the stress-strain curve of the specimen of $13.4 \mu$ thickness. When the thickness was larger than this value, the curves were the same as Fig. 2 (c) qualitatively. That is to say, the strain at the upper yield point reached about $1 \%$, and the deformation continued with constant stress up to $20 \%$ strain or so.

The stress-strain curves at room temperature are summarized as follows. After the remarkable upper yield point, plastic deformation proceeded without work-hardening up to $20 \%$, and the serration appeared when the thickness of specimen was smaller than about $10 \mu$.

\section{Elevated Temperature}

The test temperature ranged from $75^{\circ}$ to $230^{\circ} \mathrm{C}$. In Fig. 3, are shown the stress-strain curves at $75^{\circ}$, $120^{\circ}, 170^{\circ}$, and $230^{\circ} \mathrm{C}$ of specimens having $20 \mu$ thickness. The serration appeared at above $120^{\circ} \mathrm{C}$, and it became conspicuous as the temperature was increased. The periodic large serration occurred clearly above $200^{\circ} \mathrm{C}$ and it can be observed that each large serration consists of many fine waves. However, it is confirmed by many tensile tests that the serration became vague as the thickness of specimen increased, as in the case of the room temperature.

\section{Microscopic Observation}

Whiskers which were deformed at $200^{\circ} \mathrm{C}$ are shown in Photos. 1 and 2. It can be observed that the slip step does not consist of a single slip system, but rather complex slip systems. However, the direction of the slip steps observed from the macroscopic point of view can be determined as in Photo. 3. The steps could be observed only when the serration in the stress-strain curves at elevated temperatures appeared.

Figure 4 and Photo. 4 show the correspondence of the serrations with the slip steps. On the stress-strain curve, the abrupt stress drops which could be followed by the recorder pen occurred six times, and on the specimen under a microscope, six heavy slip steps were observed. Meanwhile, on the specimens thicker than about $40 \mu$ under the same condition, the periodic large serrations did not appear and the steps on the specimen turned to be unstraight lines. The strain caused only by the large slip steps obtained from the height of the steps of a ruptured whisker measured on a photomicrograph showed that the large slip deformation contributed by only about a tenth to the total tensile strain. It is evident from those measurements that the deformation proceeds not only at the localized
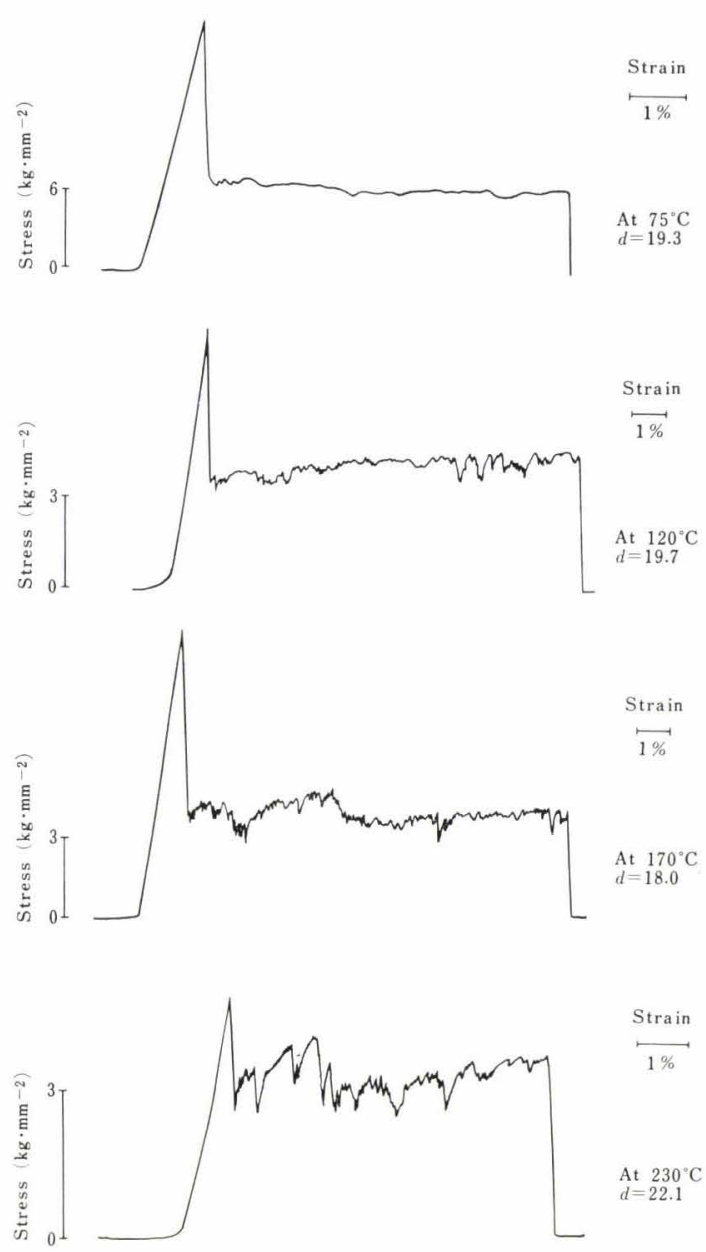

Fig. 3. Stress-strain curves with the thickness of about $20 \mu$ at various temperatures. After the sharp yield drop, the stress fluctuation appears as the temperature increases, becoming the serration. $d$ is the thickness in micron.

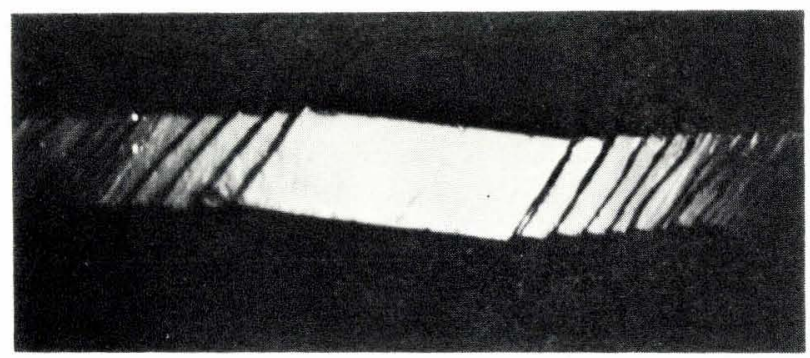

Photo. 1. The deformed whisker at $200^{\circ} \mathrm{C}$ after rupture. The large deformation steps are formed when the periodic serrations appear on the stress-strain curve. The steps do not consist of a single slip system, but rather of complicated systems. The thickness is $30 \mu . \quad(\times 630)$ $(\times 4 / 7)$ 
large slip bands but also through the specimen.

\section{Relation between Stress and Temperature}

The stresses of the sharp upper yield point which is

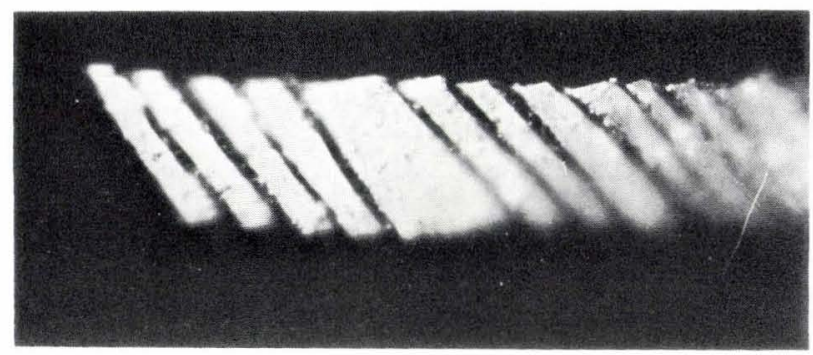

Photo. 2. The tip of the ruptured whisker by tension at $200^{\circ} \mathrm{C}$ $(\times 760)(\times 2 / 3)$

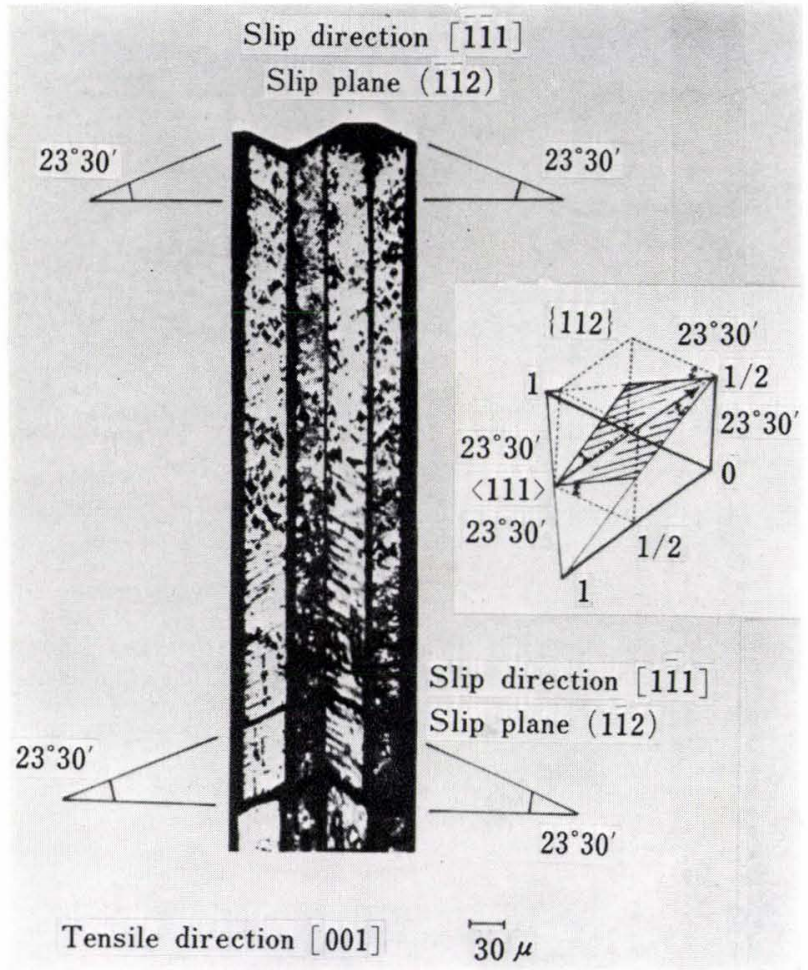

Photo. 3. The heavy deformation steps and slip lines deformed at $200^{\circ} \mathrm{C}$. When the cross section is rectangular, the growth direction is $\langle 100\rangle$, and the four lateral faces are $\{100\}$. When macroscopically observed, the slip directions and planes are $\langle 111\rangle$ and $\{112\}$. characteristic of whiskers and the lower yield point (or flow stress) were found in all the stress-strain curves that were conducted in this experiment, and the results are presented in Figs. 5 and 6 as a function of reciprocal of the thickness respectively. A considerable scatter is seen in the plots, but a good linear relationship is shown. The average strengths were calculated from those values as inversely proportional to the thickness, and the results are shown in Figs. 7 and 8. In Fig. 9, the values of the logarithm of the

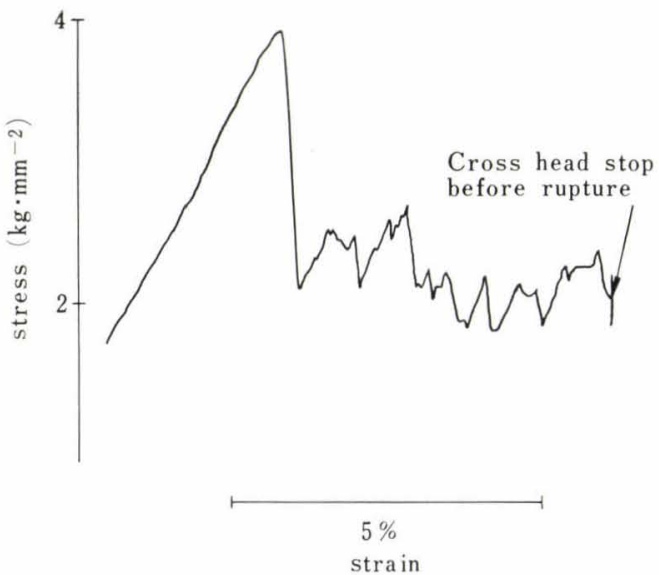

Fig. 4. The stress-strain curve of a specimen in Photo. 4. The whisker was tensile-tested at $200^{\circ} \mathrm{C}$, and stopped before the rupture occurred. Six abrupt stress drops occurred after yield, and six periodic serrations are shown. The thickness is $28.4 \mu$.

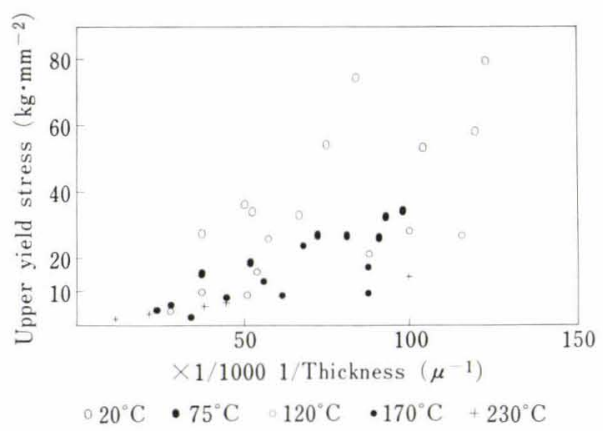

Fig. 5. Upper yield points as a function of the reciprocal of the thickness at each temperature. The thickness is the square-root of the cross sectional area.

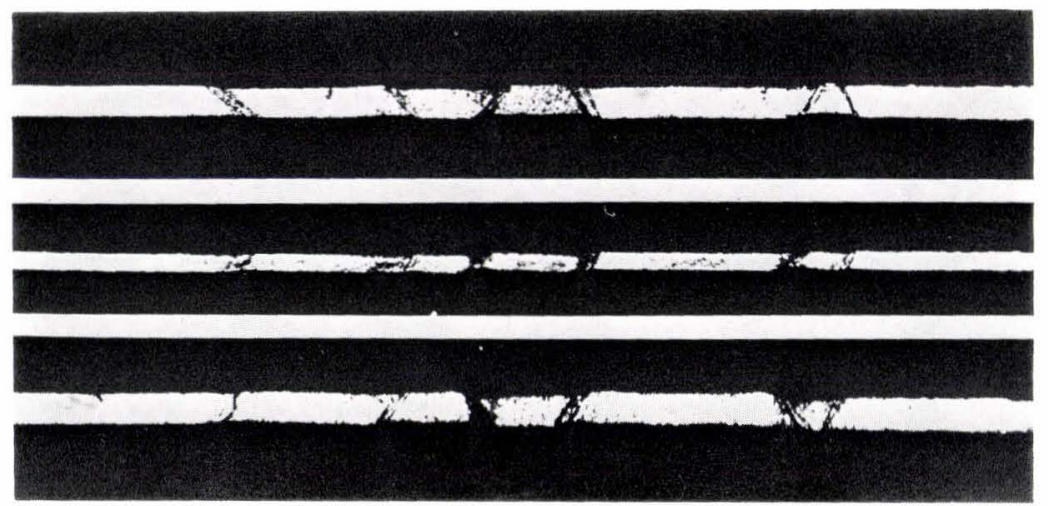

Photo. 4.

Three lateral faces of the specimen used in Fig. 4. Six largely deformed places can be observed. Such a large deformation step was not observed on specimens immediately after the yield drop before the first serration. $(\times 130)(\times 2 / 3)$ 


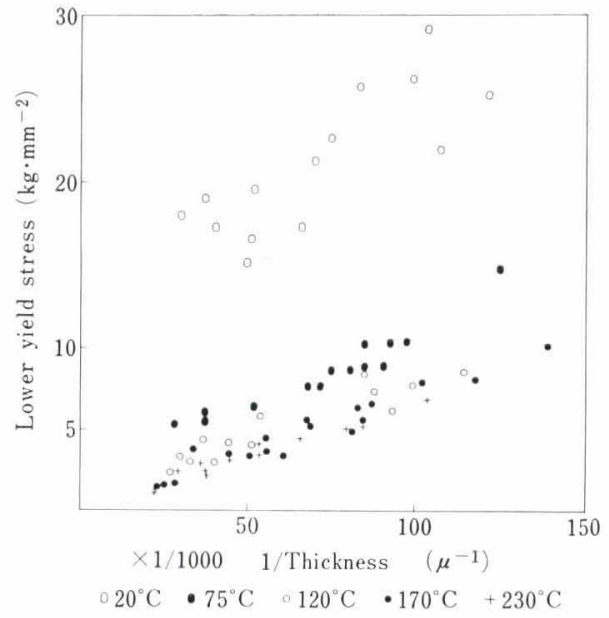

Fig. 6. Lower yield points as a function of the reciprocal of the thickness at each temperature. The thickness is the square-root of the cross sectional area.

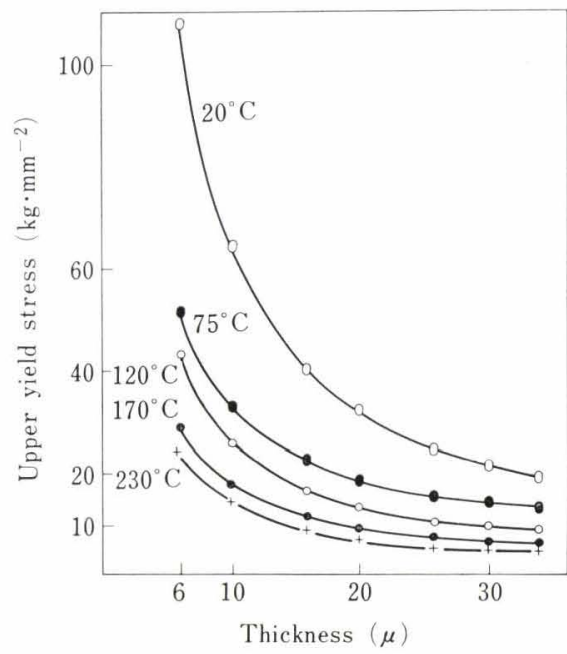

Fig. 7. Average upper yield stresses vs. the thickness at each temperature. Each value is calculated from Fig. 5 using the equation $\sigma=a / d+b$, where $\sigma$ is the average upper yield stress, $d$ the thickness, $a$ and $b$ the constants evaluated as follows; $20^{\circ} \mathrm{C} ; 650.3$ and $-0.6,75^{\circ} \mathrm{C} ; 280.9$ and $4.9,120^{\circ} \mathrm{C} ; 259.0$ and $0.4,170^{\circ} \mathrm{C} ; 165.1$ and $1.0,230^{\circ} \mathrm{C}$; 149.1 and -0.6 .

average stresses at $20 \mu$ are plotted against the reciprocal of the absolute temperature. In the case of the upper yield point a good linear relation exists. The lower yield points are expressed by two straight lines that intersect at about $120^{\circ} \mathrm{C}$ from which the serration and the slip steps began to appear in this test.

\section{Discussion}

\section{The Slip Bands and the Serrations}

In the discussions by Yoshida et al. ${ }^{9)}$ on the plastic deformation of copper whiskers with regard to the stress-strain curves, they reasoned the serration as follows; the formation of a new slip band caused the stress drops due to the high dislocation velocity and rapid multiplications in the new band and subsequently

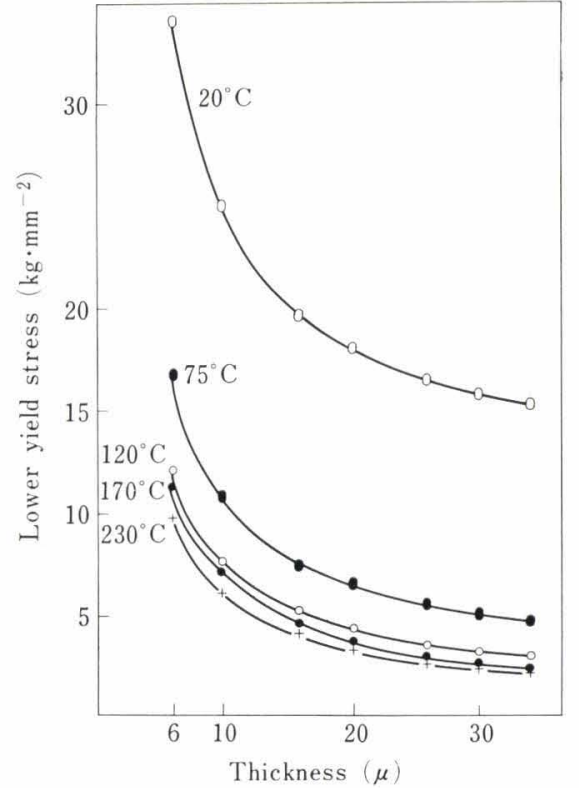

Fig. 8. Average lower yield stresses $v s$. the thickness at each temperature. Each value is calculated from Fig. 6 using the equation $\sigma=a / d+b$, where $\sigma$ is the average lower yield stress, $d$ the thickness, $a$ and $b$ the constants evaluated as follows; $20^{\circ} \mathrm{C}$; 137.3 and $11.2,75^{\circ} \mathrm{C}$; 88.7 and 2.0 , $120^{\circ} \mathrm{C} ; 67.6$ and $0.9,170^{\circ} \mathrm{C} ; 68.9$ and $0.3,230^{\circ} \mathrm{C} ; 55.2$ and 0.6

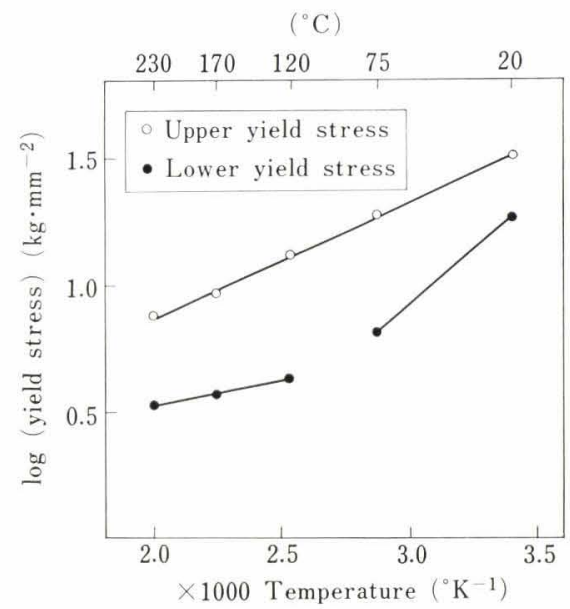

Fig. 9. Logarithm of the yield stresses $v s$. the reciprocal of the absolute temperature at the thickness of $20 \mu$. The upper yield stress represents the linear relationship and the lower yield stress changes the gradient at the temperature from which the serration appeared as shown in Fig. 3.

the new band work-hardened until a next slip band formed. Meanwhile, Keh et al. ${ }^{10)}$ and Brindley et al.11),12) reported the dynamic strain ageing of iron and steel, and concluded that the serrations which appeared in the temperature range of $100^{\circ}$ to $300^{\circ} \mathrm{C}$ were correlated to a small amount of the interstitial solute.

Generally speaking, the deformation phenomenon of bcc metals is distinguished from fcc metals, because of complications of slip systems. However, deformation of iron whiskers in this experiment is qualitatively in a considerably good accordance with the case of 
copper whiskers which showed the serrations on thinner specimens. Coleman ${ }^{3)}$ carried out experiments of deformation on iron whiskers by bending at $77^{\circ} \mathrm{K}$ and room temperature, and showed prominent slip bands both on $\{110\}$ and $\{112\}$ planes by the use of etching methods of annealed specimens.

In the stress-strain curves of iron whiskers in the present test, there are two distinguished phenomena about the serration. One is the large serrations, each of which consists of the increasing stress and final abrupt stress drop, and another is the fine serrations which are on the large serration. It is considered from the experimental facts that the former corresponds to the heavy slip steps which are characteristic of the test at elevated temperatures and the latter is discussed as follows.

When the plastic deformation proceeds in the bcc structure, the following mechanism is commonly considered to be reasonable. When stress is applied, slips occur at first mainly on some slip planes on which the shearing stress is higher, but, on the other hand, relatively small slips on other planes may be accompanied. Furthermore, the double cross slips arise. As a result, the heavy slip band which does not consist of a single slip plane will be formed. However, structure of the slip band is considered to become relatively simpler on thinner specimens. The deduction about the deformation process of bcc metals described above will give reasons for the small serrations of iron whiskers following the model of copper whiskers which show the Lüders deformation before the workhardening stage. But, iron whiskers do not produce the serrations in thicker specimens than about $10 \mu$ though the deformation proceeds by the Lüders band. Such a different manner between iron and copper whiskers may plausibly be attributed to the difference of charactors of dislocations in both metals.

In the stress-strain curves at elevated temperatures of specimens $20 \mu$ in thickness, the serrations occur above $120^{\circ} \mathrm{C}$, and the lower yield stress (flow stress) shows a strong temperature dependence below $120^{\circ} \mathrm{C}$ and no appreciable temperature dependence above it. Such a tendency of the flow stress for the temperature dependence is in good agreement with the case of iron single crystals reported by Takeuchi et al. ${ }^{13)}$ Meanwhile, it has been generally accepted that the flow stress will be given by the sum of two terms, one of which is independent of temperature after correction for the temperature dependence of the shear modulus, and another is the temperature dependent contribution which is thought to be due to the stress required to make jogs during intersection of forest dislocations. ${ }^{14}$ ) From those arguments it is considered that the slip band can be easily formed in the temperature range which shows the serrations, because by the thermal activation dislocations easily overcome obstacles which are due to the formation of jogs, and consequently the stress is relatively low compared to the temperature range which shows no serrations. Then, it is reasonable to think that the flow stress will be due to slips on the nearly single slip system and represent the weak temperature dependence as the elastic parameters of iron single crystals do. ${ }^{15)}$

The role of interstitial atoms such as carbons or nitrogens have been studied, and Keh et al. ${ }^{10)}$ concluded that the serrations which appeared in the temperature range of $100^{\circ}$ to $200^{\circ} \mathrm{C}$ were correlated to a small amount of the interstitial solute. Then, such solutes in iron whiskers must be carefully examined. However, specimens of the thickness about $0.5 \mathrm{~mm}$ employed in their experiments are quite different in size from our tests. At elevated temperatures in this test the serrations disappeared as the thickness increased, and the stress-strain curves is similar to that of the specimen of $20 \mu$ thickness at $75^{\circ} \mathrm{C}$. It can be thought from those results that the serrations appeared in iron whiskers are different in nature from the impurity effect.

Meanwhile, the periodic large serrations which occurred with the large slip steps may be due to another mechanism. It may be due to the abrupt changes of the strain rate caused by the occurrence of slip steps. But detailed mechanism to form the periodic large slip steps is not clear and it must be made clear in future.

\section{Acknowledgements}

The authors had discussions on the experimental results with Taira Suzuki, Shin Takeuchi, Hideo Kojima, and Eiichi Kuramoto at The Institute for Solid State Physics in Tokyo. We express our thanks to their useful and kind suggestions.

\section{REFERENCES}

1) S. S. Brenner: J. Appl. Phys., 27 (1956), 1484.

2) W. L. Piotrowski, D. C. Larson, and J. W. Beams: J. Appl. Phys., 37 (1966), 3153.

3) R. V. Coleman: Growth and Perfection of Crystals, (1958), 239, John Wiley and Sons, New York.

4) K. Yoshida, M. Yamamoto, and T. Onozuka: J. Phys. Soc. Japan, 22 (1967), 668.

5) W. G. Johnston: J. Appl. Phys., 33 (1962), 2716.

6) N.J. Petch: JISI, 174 (1953), 25.

7) S. S. Brenner: Acta Met., 4 (1956), 62.

8) A. Okura and K. Kaneko: To be published.

9) K. Yoshida, Y. Gotoh, and M. Yamamoto: J. Phys. Soc. Japan, 24 (1968), 1099.

10) A. H. Keh, Y. Nakada, and W. C. Leslie: Dislocation Dynamics, edited by A. R. Rosenfield et al., (1968), 381, McGrow-Hill, New York.

11) B. J. Brindley and J. T. Barnby: Acta Met., 14 (1966), 1765.

12) B. J. Brindley and J. T. Barnby: Acta Met., 16 (1968), 41.

13) T. Takeuchi, R. Honda, K. Iwayama, and T. Taoka: Japan. J. Appl. Phys., 6 (1967), 1282.

14) P. B. Hirsch and D. H. Warrington: Phil. Mag., 6 (1961), 735.

15) K. Nakamura: Tohoku Univ. Sci.Rep., (1) 25 (1936), 364. 